\title{
REVIEW
}

\section{An Update on Triptorelin: Current Thinking on Androgen Deprivation Therapy for Prostate Cancer}

Axel S. Merseburger · Marie C. Hupe

Received: April 1, 2016/ Published online: May 31, 2016

(C) The Author(s) 2016. This article is published with open access at Springerlink.com

\begin{abstract}
Androgen deprivation therapy (ADT) is the mainstay palliative treatment for men with locally advanced and metastatic prostate cancer, and aims to reduce testosterone to levels obtained by surgical castration. Use of gonadotropin-releasing hormone (GnRH) agonists predominates among the ADT options. The GnRH agonist, triptorelin is a first-line hormonal therapy that has demonstrated efficacy and safety in clinical

inevitable progression to castration-resistant prostate cancer (CRPC) in most patients receiving $\mathrm{ADT}$, monitoring of testosterone levels needs to improve in routine practice and physicians should not overlook the benefits of continued ADT in their patients when introducing one of the various new treatment options for CRPC. For improved survival outcomes, there remains a need to tailor ADT treatment regimens, novel hormonal agents and chemotherapy according to the individual patient with advanced prostate cancer.
\end{abstract} trials of patients with locally advanced non-metastatic or metastatic disease. Sustained-release 1-, 3- and 6-month formulations of triptorelin, administered intramuscularly or subcutaneously, have been developed to provide improved flexibility and convenience for the patient. Head-to-head studies of GnRH agonists are lacking in the field of prostate cancer. Despite the

Enhanced content To view enhanced content for this article go to http://www.medengine.com/Redeem/75D4 F06043F0A7DE.

A. S. Merseburger $(\bowtie) \cdot$ M. C. Hupe

University Hospital Schleswig-Holstein, Lübeck,

Germany

e-mail: axel.merseburger@uksh.de
Keywords: Androgen deprivation therapy; Oncology; Prostate cancer; Sustained-release formulations; Triptorelin

\section{INTRODUCTION}

Prostate cancer is the most frequently occurring cancer among European men, with an estimated incidence of 416,700 (varying from 25 to 193 per 100,000 populations in different European countries) and an estimated 92,200 deaths in 2012 [1]. In the USA, incidence of prostate cancer is within this European range at 
138 per 100,000 populations according to the Surveillance, Epidemiology, and End Result program [2]. Hereditary factors are important for determining the risk of developing prostate cancer and exogenous factors may have an impact on the risk of progression. However, in general, the risk factors for prostate cancer are poorly understood and consequent advice on prevention is not possible [3]. Therefore, the management of prostate cancer focuses on treating the disease, and the hormone dependence of prostate cancer has been recognized for decades [4]. As a consequence, testosterone suppression has been the standard palliative treatment in men with advanced prostate cancer for many years. Orchiectomy is a simple, low-cost surgical procedure that effectively and quickly achieves castration, but because it is irreversible and does not allow intermittent treatment, it has become less popular than hormonal therapies among patients.

The selection of appropriate treatment is mainly dependent on the stage of disease and the risk of progression. Prostate cancer is generally described as localized, locally advanced (when the tumor has extended beyond the capsule of the prostate) and metastatic disease, and is classified using the Tumor-lymph Nodes-Metastasis (TNM) system [5]. Patients are also categorized into low, high, or intermediate risk of progression according to clinical stage, Gleason score, and prostate-specific antigen (PSA) level [6], and this will continue with the adoption of the recent International Society of Urological Pathology (ISUP) modified Gleason grading patterns [7]. However, a recent assessment of a large cohort found that while high levels of PSA $(>100 \mathrm{ng} / \mathrm{ml})$ at diagnosis were associated with a reduction in survival after 5 and 10 years, within this high-risk group PSA level was not associated with prostate cancer-specific mortality [8]. Gleason score and the presence of metastasis were the strongest predictors of prostate cancer-specific mortality in this group with high PSA at presentation [8]. What is clear is that patients classified as having low or intermediate risk prostate cancer (Gleason score $<8$ and PSA $<20 \mathrm{ng} / \mathrm{ml}$ ) may have a 10 -year prostate cancer-specific mortality of $<5 \%$ [9, 10], and avoiding unnecessary treatment is a challenge in these patients $[11,12]$. Patients with high-risk prostate cancer make up a considerable proportion of newly diagnosed patients and have much higher mortality rates, and therefore, the challenge in these men is to increase overall survival while reducing any adverse effects of treatment. However, this high-risk population is heterogeneous and more information is needed on the validity of suggested prognostic indicators, such as the number and location of bone metastases, visceral metastases, Gleason score, and the initial PSA level [3, 13].

This article reviews the current and ongoing role of androgen deprivation therapy (ADT) in the management of prostate cancer, with a particular focus on clinical trial and real-world evidence supporting the use of the gonadotropin-releasing hormone (GnRH) agonist triptorelin in men with locally advanced or metastatic prostate cancer. As such, this article is based on previously conducted studies, and does not involve any new studies of human or animal subjects performed by any of the authors.

\section{THE ROLE OF ADT IN PROSTATE CANCER MANAGEMENT}

ADT aims to reduce testosterone levels to the levels achieved with surgical castration [defined 
as $\quad<50 \mathrm{ng} / \mathrm{dl} \quad(<1.7 \mathrm{nmol} / \mathrm{l})$ by regulatory authorities and used in clinical trials, but $<20 \mathrm{ng} / \mathrm{dl}$ may be a more clinically meaningful definition of castration] [3].

ADT is recommended for patients with locally advanced prostate cancer and metastatic prostate cancer [3]. In the case of locally advanced prostate cancer, ADT is recommended only when patients are unwilling or unable to receive any form of local treatment and who are symptomatic or asymptomatic with a PSA doubling time (PSA-DT) <12 months and a poorly differentiated tumor. ADT is also recommended for lymph node positive (N1) prostate cancer whether newly diagnosed or after extended lymph node dissection. In both situations, additional radiation therapy may have a role. ADT using GnRH agonists should be combined at treatment initiation with the short-term administration of anti-androgens to prevent flare-up of symptoms due to the initial pituitary stimulation and increase in testosterone levels [3].

Androgen deprivation can be achieved with a number of different types of ADT, including GnRH agonists, GnRH antagonists, and oestrogens. Anti-androgens are also sometimes used to inhibit the action of androgens. GnRH agonists, of which the most widely used include triptorelin, goserelin, and leuprolide, stimulate gonadotropins from the anterior pituitary gland and the production of testosterone in men, but continued administration leads to the downregulation of pituitary GnRH receptors, which quickly results in the suppression of gonadotropins [luteinising hormone (LH) and follicle stimulating hormone (FSH)] followed by a decrease in testosterone levels [14, 15]. GnRH antagonists (e.g., degarelix) competitively bind to the pituitary GnRH receptors and directly inhibit the release of gonadotropins and lead to reduced testosterone levels [16]. Oestrogens induce pituitary suppression of gonadotropin secretion and inhibit the production of androgens in the testicles but are rarely used due to their side effect profile [17]. Anti-androgens, which bind to androgen receptors and thereby block the effect of endogenous androgens, are used in combination with GnRH agonists to achieve complete androgen blockade (CAB) [18]. In the short term, the concomitant use of anti-androgens prevents the flare-up that can occur when initiating GnRH agonist therapy [18]. Anti-androgens include bicalutamide, flutamide, and the more recently developed enzalutamide [19]. Moreover, abiraterone is a novel androgen synthesis inhibitor that has been shown to block androgen synthesis in adrenal glands and prostate cancer cells. Both abiraterone and enzalutamide are generally indicated for second-line treatment when castration resistance develops with ADT [20-22].

While ADT is effective for reducing testosterone and PSA levels, almost all men treated in the long term develop castrate-resistant prostate cancer (CRPC) $[23,24]$, with more than $80 \%$ exhibiting bone metastases upon diagnosis of CRPC.

\section{TRIPTORELIN AS ADT}

The most widely used ADT in clinical practice is GnRH agonist therapy, and one frequently prescribed agent is triptorelin (Decapeptyl ${ }^{\circledR}$, Pamorelin $^{\circledR}$, Diphereline $^{\circledR}$, Arvekap $^{\circledR}$, Ipsen, Paris, France). In line with European Association of Urology (EAU) guidelines [3], triptorelin is indicated as the first-line 
hormonal therapy in patients with locally advanced non-metastatic or metastatic disease as an alternative to surgical castration; and as add-on to external-beam radiation therapy.

Triptorelin is administered to patients in the form of acetate or pamoate (also known as embonate) salts, and in response to the need for ADT regimens that improve convenience and treatment adherence, sustained-release 1-month (3 or $3.75 \mathrm{mg}$ ), 3-month (11.25 mg), and 6-month (22.5 $\mathrm{mg})$ formulations of triptorelin have been developed (Fig. 1) [25-27]. Sustained-release formulations of triptorelin comprise microparticles of the decapeptide incorporated within a biocompatible and biodegradable copolymer (polylactide-co-glycolide) [28].

\section{Pharmacokinetics}

Following intravenous bolus administration, triptorelin is distributed and eliminated by hepatic and renal routes according to a three-compartment model that corresponds to plasma half-lives of $6 \mathrm{~min}, 45 \mathrm{~min}$, and $3 \mathrm{~h}$ [27]. Sustained-release intramuscular administration of triptorelin initially stimulates LH and FSH secretion, with the subsequent production of testosterone [27]. Bioequivalence studies suggest a maximal increase in testosterone at around 4 days post-triptorelin administration. Testosterone levels progressively decline after this initial increase with continuous exposure to triptorelin [27]. Romero et al. developed a (a)<smiles>CC(=O)O</smiles>

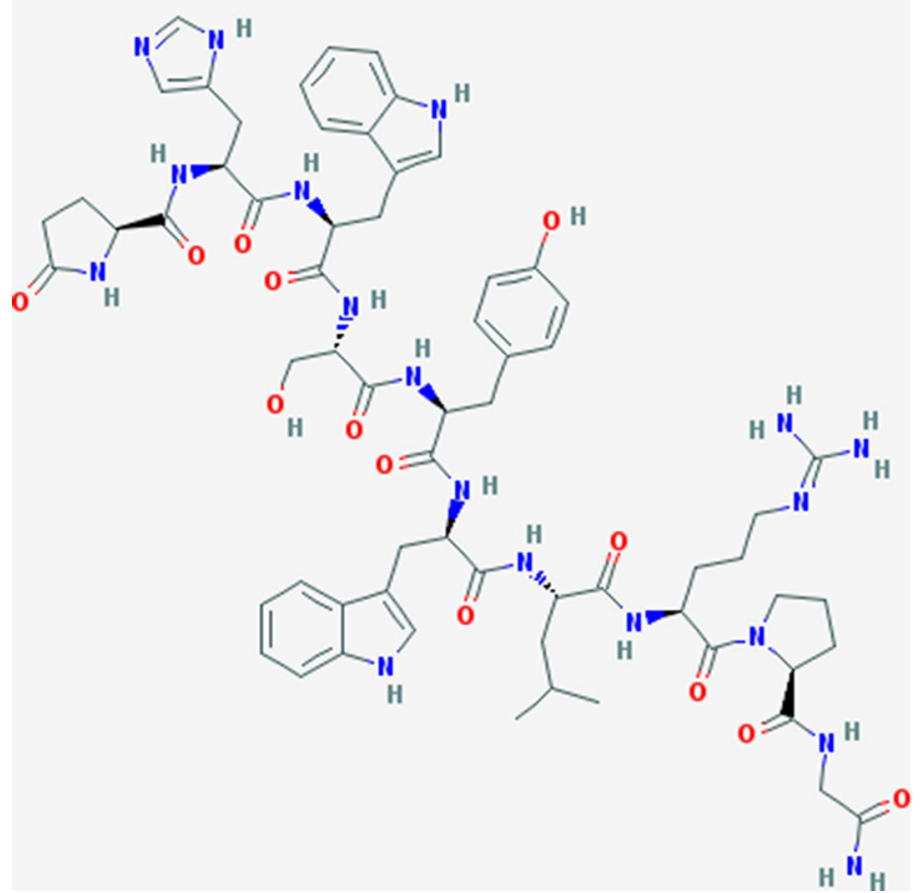

(b)
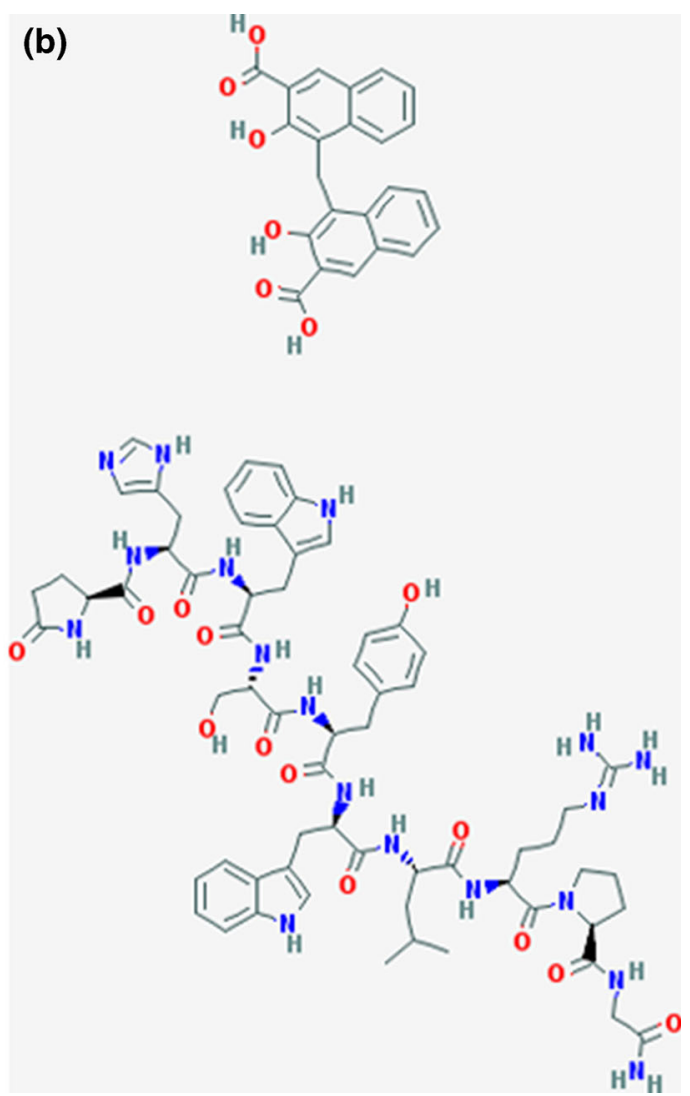

Fig. 1 Structure of triptorelin acetate (a) and pamoate $(\mathbf{b})[82,83]$ 
pharmacokinetic/pharmacodynamics model indicating that $95 \%$ of patients with steady-state concentrations of triptorelin $\left(C_{\mathrm{min}}\right)$ higher than $0.0609 \mathrm{ng} / \mathrm{ml}$ were kept castrated [29].

Triptorelin is usually administered by IM injection. After the first month, mean serum levels of triptorelin are stable at $0.06 \mathrm{ng} / \mathrm{ml}$ for approximately 12 weeks after a single IM injection of a triptorelin pamoate 3-month formulation, with mean (standard deviation) $C_{\max }$ of $35.7 \mathrm{ng} / \mathrm{ml}(18.3 \mathrm{ng} / \mathrm{ml})$ and $C_{\min }$ of $0.063 \mathrm{ng} / \mathrm{ml}$ (range 0.021-0.174 ng/ml) [30]. A single IM administration of the 6-month formulation of triptorelin pamoate produced a $C_{\max }$ of $40.0 \mathrm{ng} / \mathrm{ml}$ (range $22.2-76.8 \mathrm{ng} / \mathrm{ml}$ ) [15].

Patients are also offered greater flexibility by the availability of subcutaneous (SC) injections of triptorelin [31]. The IM route of administration may not be suitable for all patients (for example, the risk of excessive bleeding or haematomas in those receiving anticoagulants) [32], and so SC injections provide an alternative delivery option. The key pharmacokinetic parameters (such as $C_{\max }$ and $C_{\text {min }}$ ) with the $\mathrm{SC}$ injection of a triptorelin pamoate $11.25 \mathrm{mg} 3$-month formulation are in the same range as observed for the IM injection $[30,31]$.

\section{Clinical Efficacy}

A significant body of evidence supports the efficacy and safety of sustained-release formulations of triptorelin for the treatment of patients with locally advanced non-metastatic or metastatic prostate cancer (Table 1 ).

The biochemical effectiveness of ADT is measured by determining if testosterone levels are reduced by treatment to castrate levels (serum testosterone $<50 \mathrm{ng} / \mathrm{dl}$ or $<1.7 \mathrm{nmol} / \mathrm{l}$ ).
In addition, more stringent definitions of castration have been proposed, such as serum testosterone $<20 \mathrm{ng} / \mathrm{dl}$ [33]. Other cut-offs, such as 30 or $32 \mathrm{ng} / \mathrm{dl}$, have also been proposed [34-36]. PSA levels are also utilized as a measure of treatment response. However, PSA measurement has many limitations; for example, there is little precision on the predictive value of PSA levels, there is no consensus on the magnitude or duration of PSA decline that can be used to define response, and PSA kinetics have little value in guiding management decisions. Nevertheless, in the absence of better surrogate markers, PSA decline is used as a secondary efficacy criterion in clinical trials of ADT. Ultimately, a decrease in testosterone level remains the primary biochemical surrogate efficacy parameter of medical castration.

Following promising data from early trials of depot formulations of triptorelin [37], the ability of the triptorelin $3.75 \mathrm{mg}$ 1-month and the triptorelin $11.25 \mathrm{mg} 3$-month formulations to achieve castration 3-4 weeks after administration and to maintain it between the injections was demonstrated in key clinical trials encompassing 14-140 men with advanced prostate cancer [30, 38-41]. In the largest of these studies, castrate levels of testosterone were reached after 28 days in $91.2 \%$ of 140 men randomized to treatment with the triptorelin $3.75 \mathrm{mg}$ 1-month formulation [40]. Moreover, in an open-label, non-comparative, Phase III study of 120 men with locally advanced or metastatic prostate cancer, the triptorelin $22.5 \mathrm{mg}$ 6-month formulation was shown to achieve castrate levels of testosterone in $97.5 \%$ of patients after 28 days and in $98.3 \%$ after 12 months [15]. Similarly, $>90 \%$ of patients achieved castrate levels of testosterone 1, 3, and 6 months after injection of triptorelin $22.5 \mathrm{mg}$ in the recent 


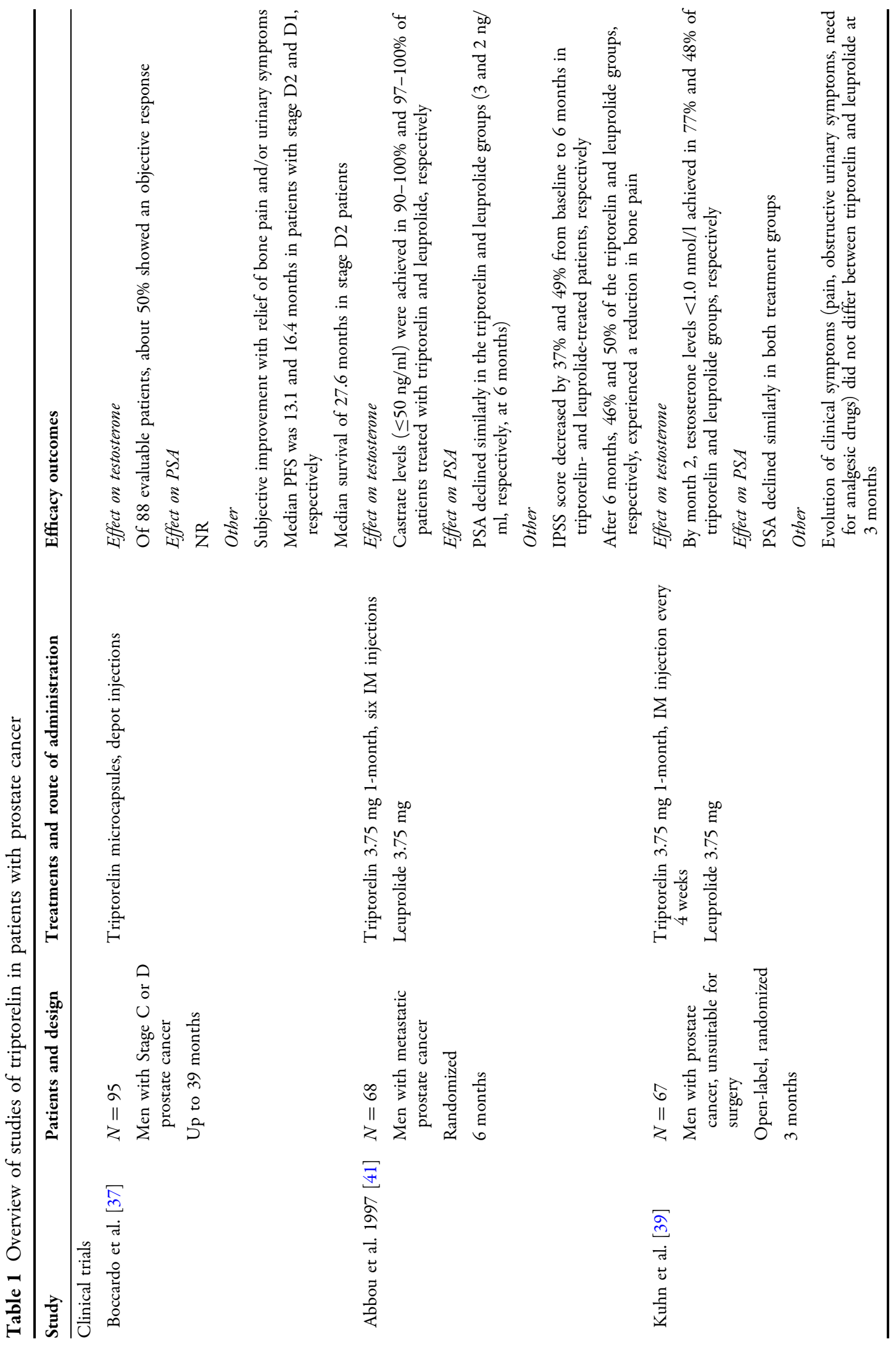




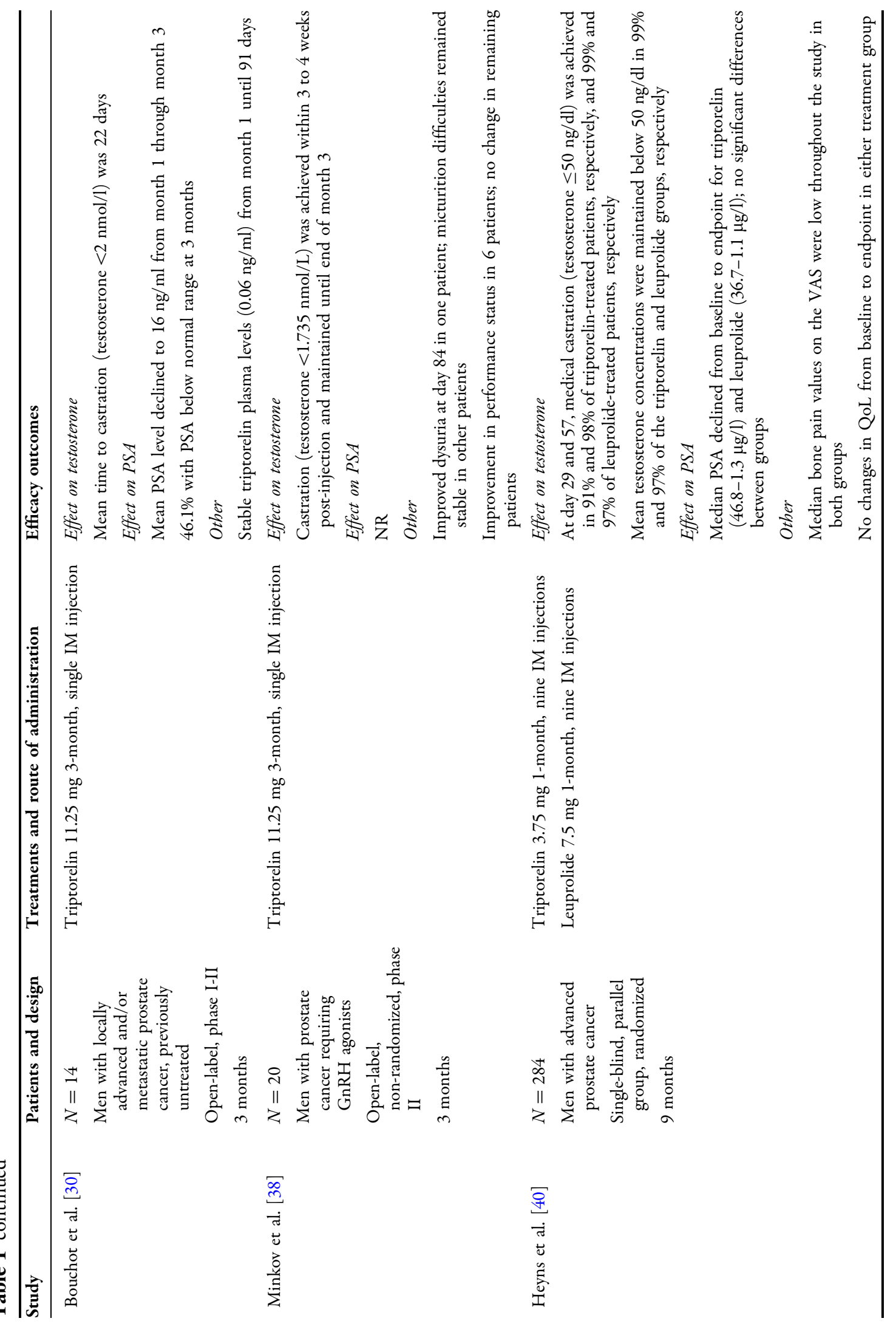




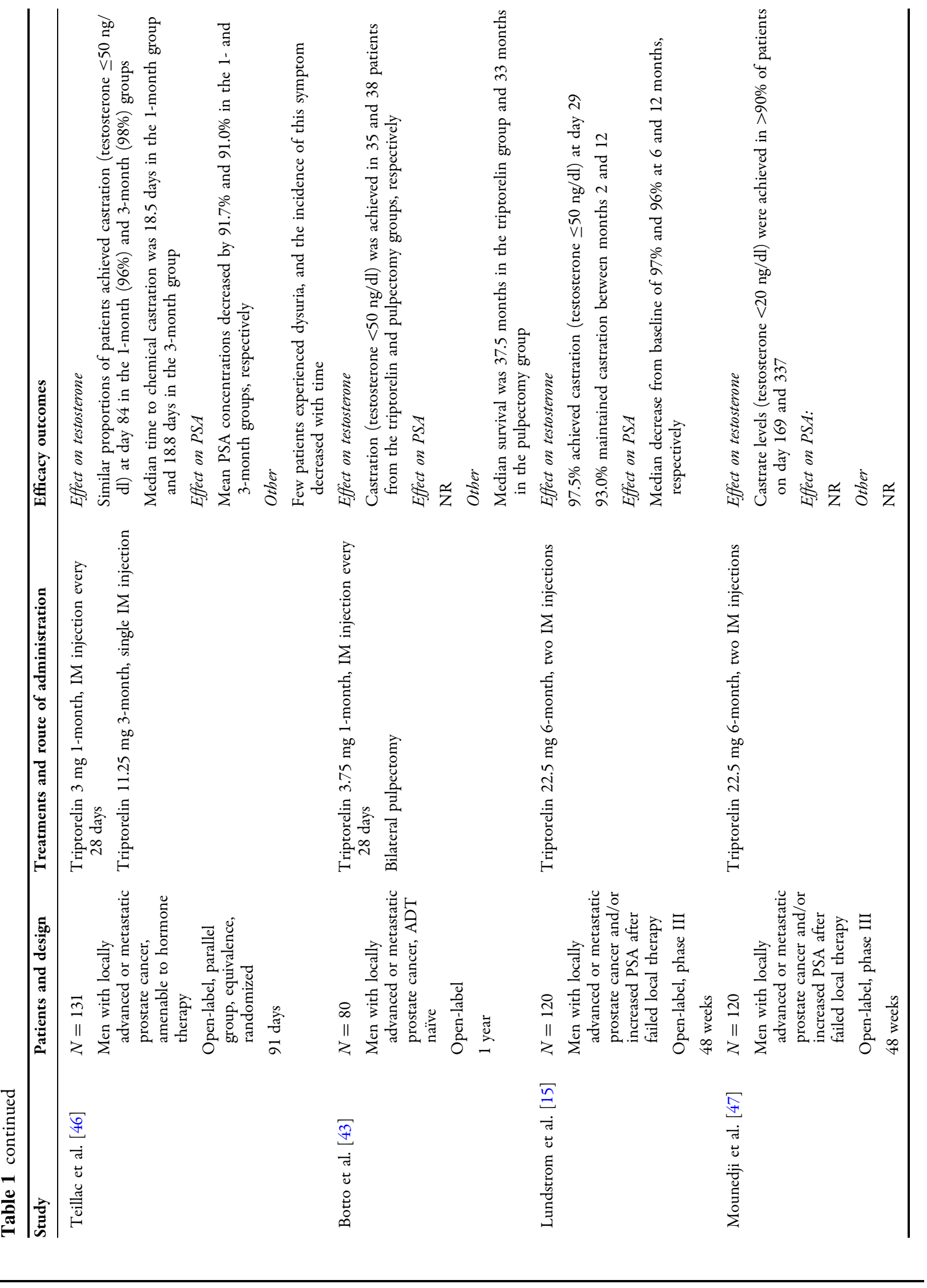




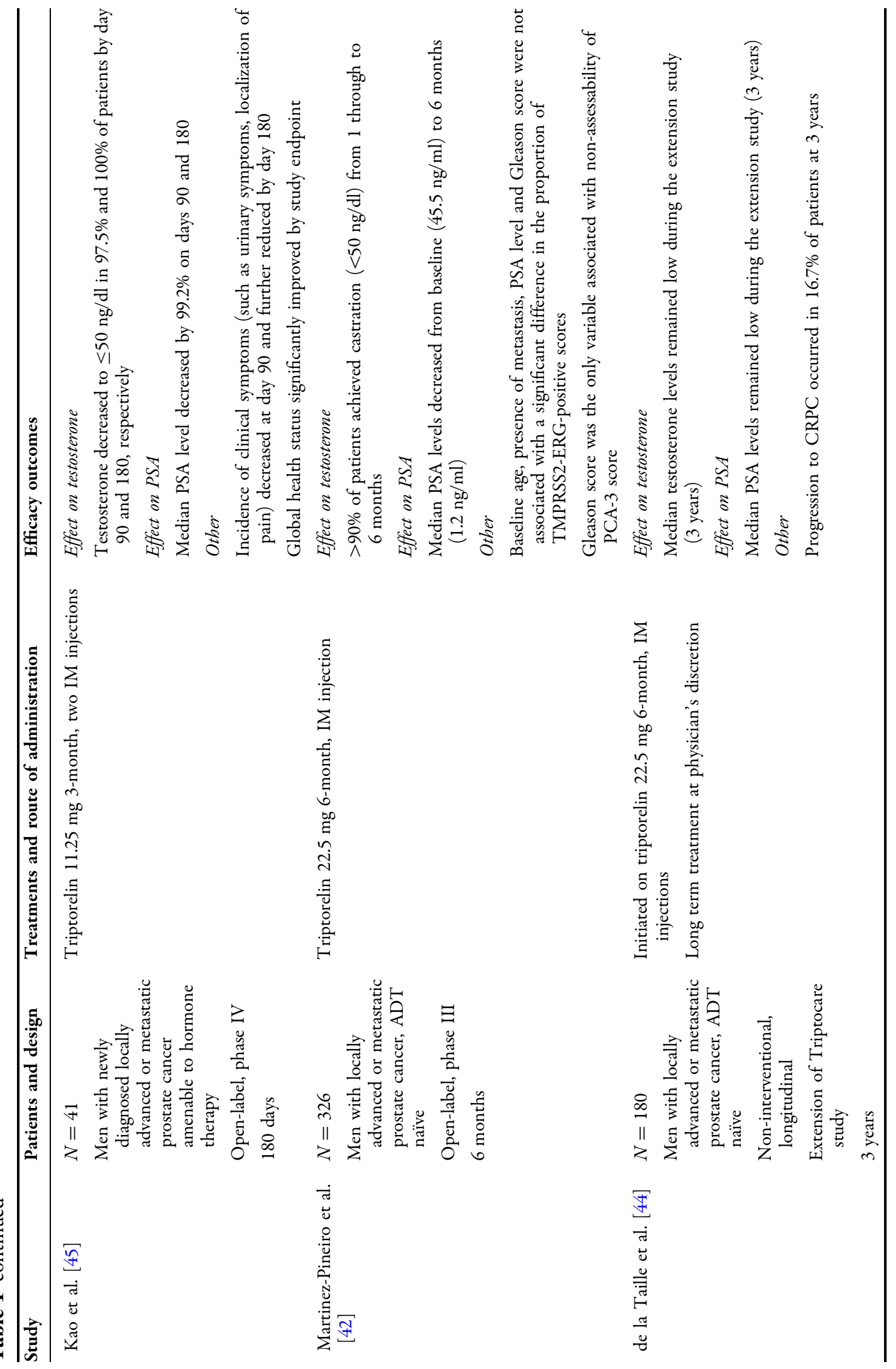




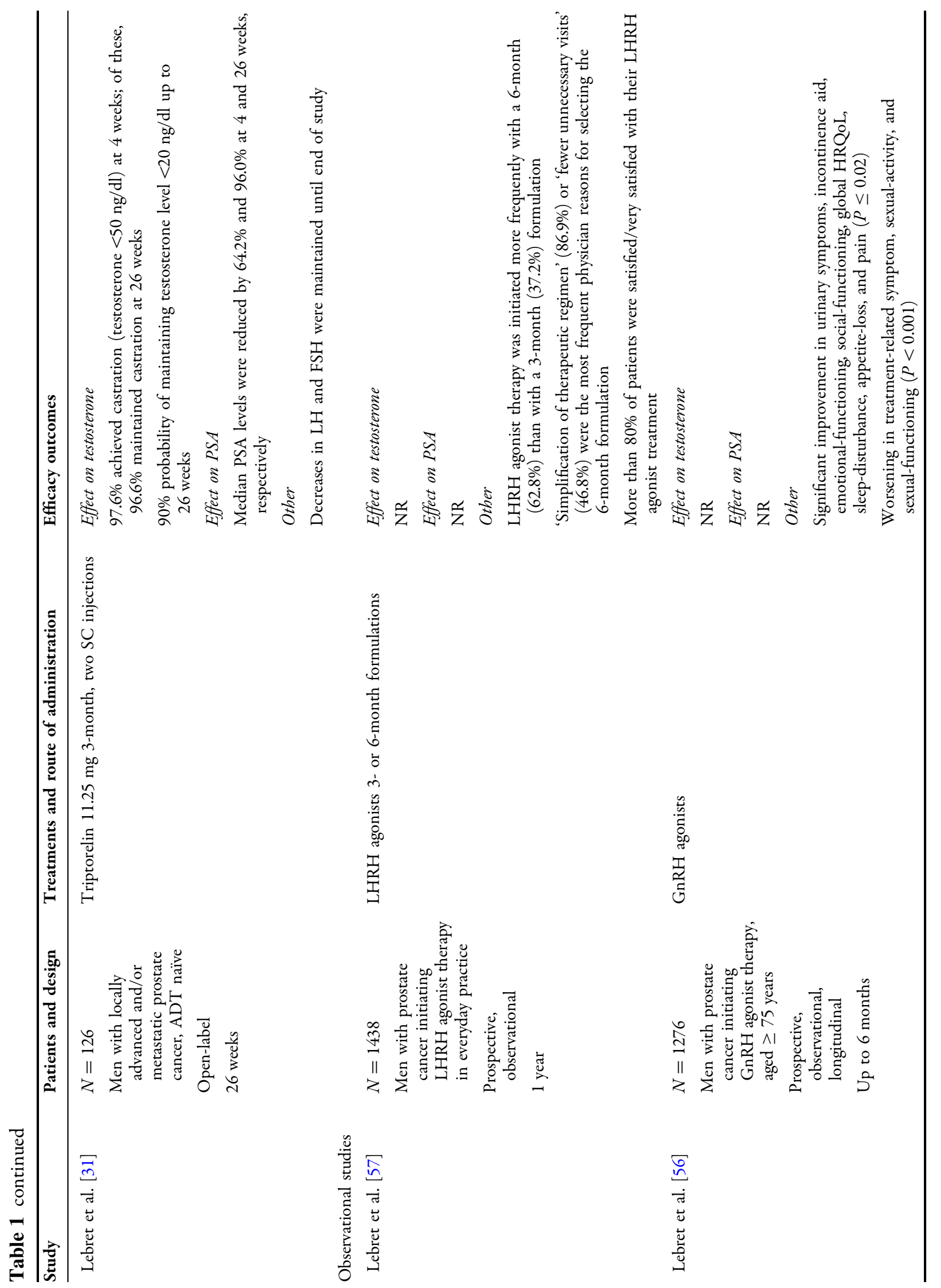




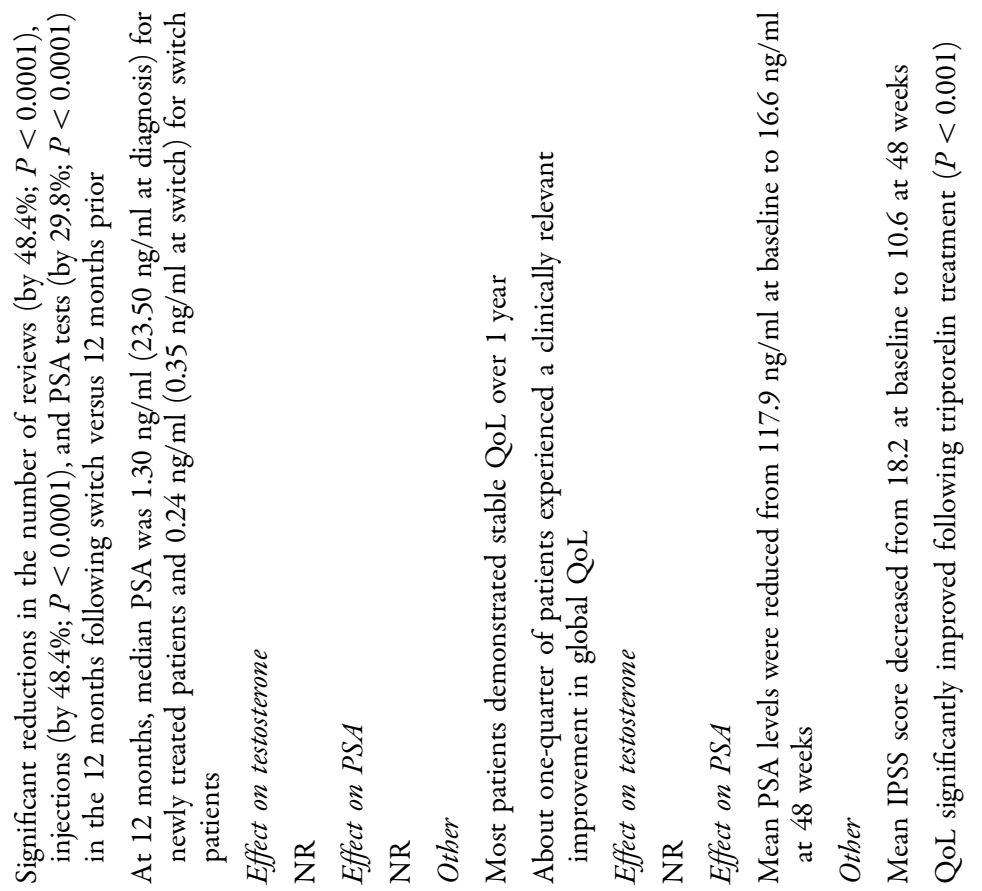

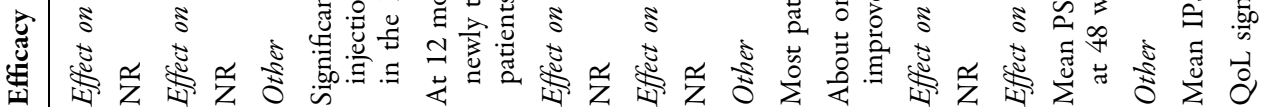
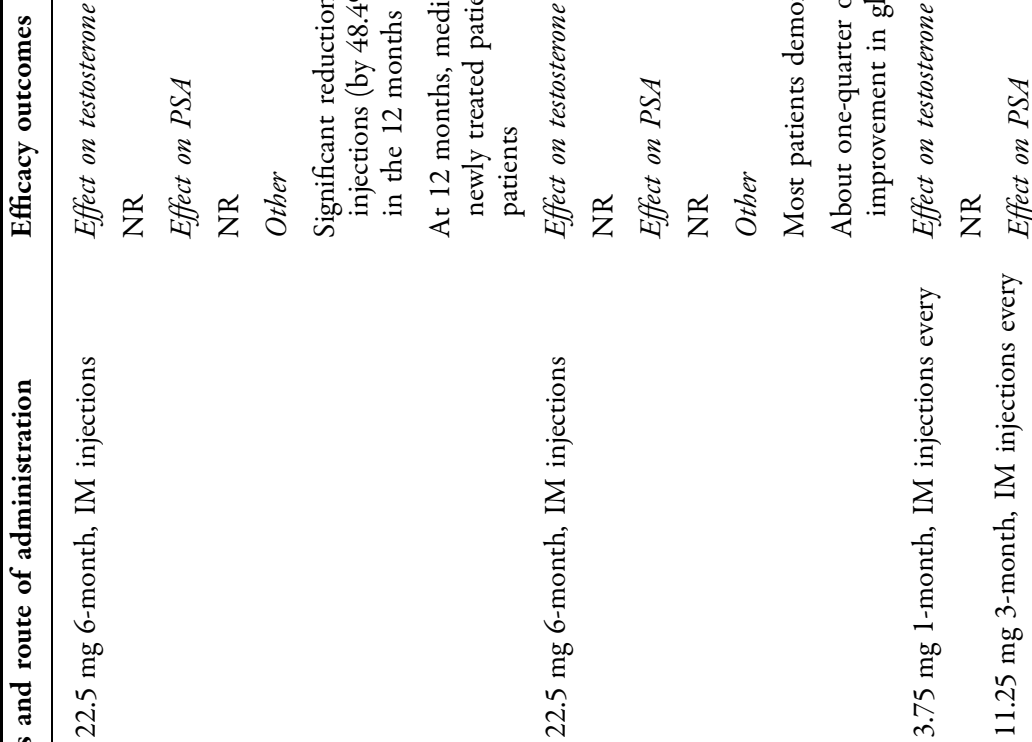

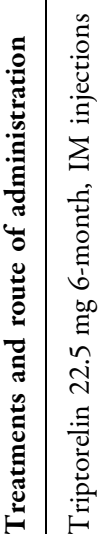

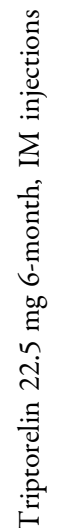

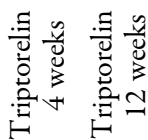

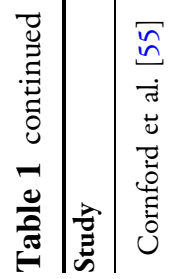

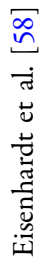

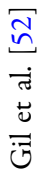




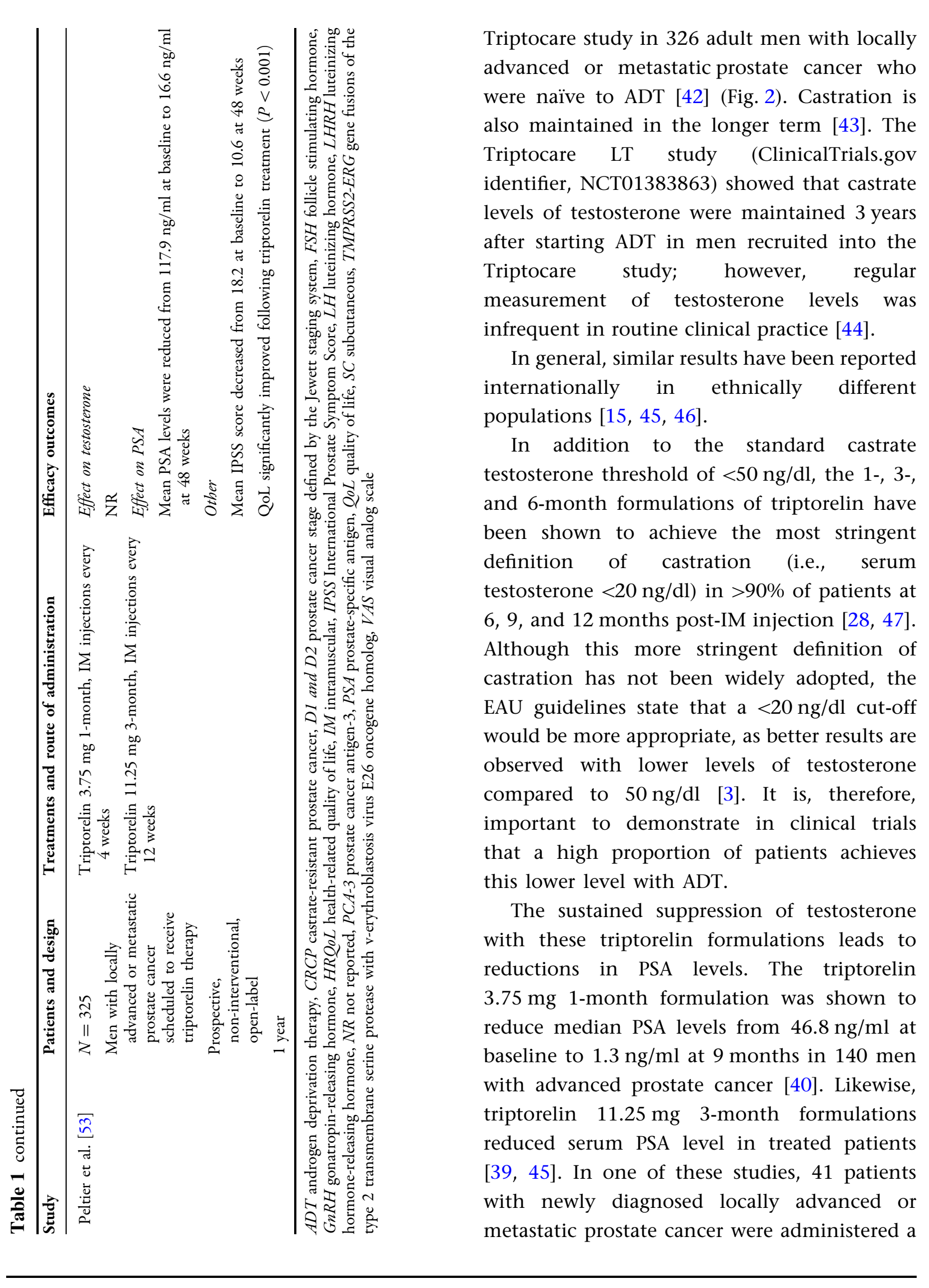



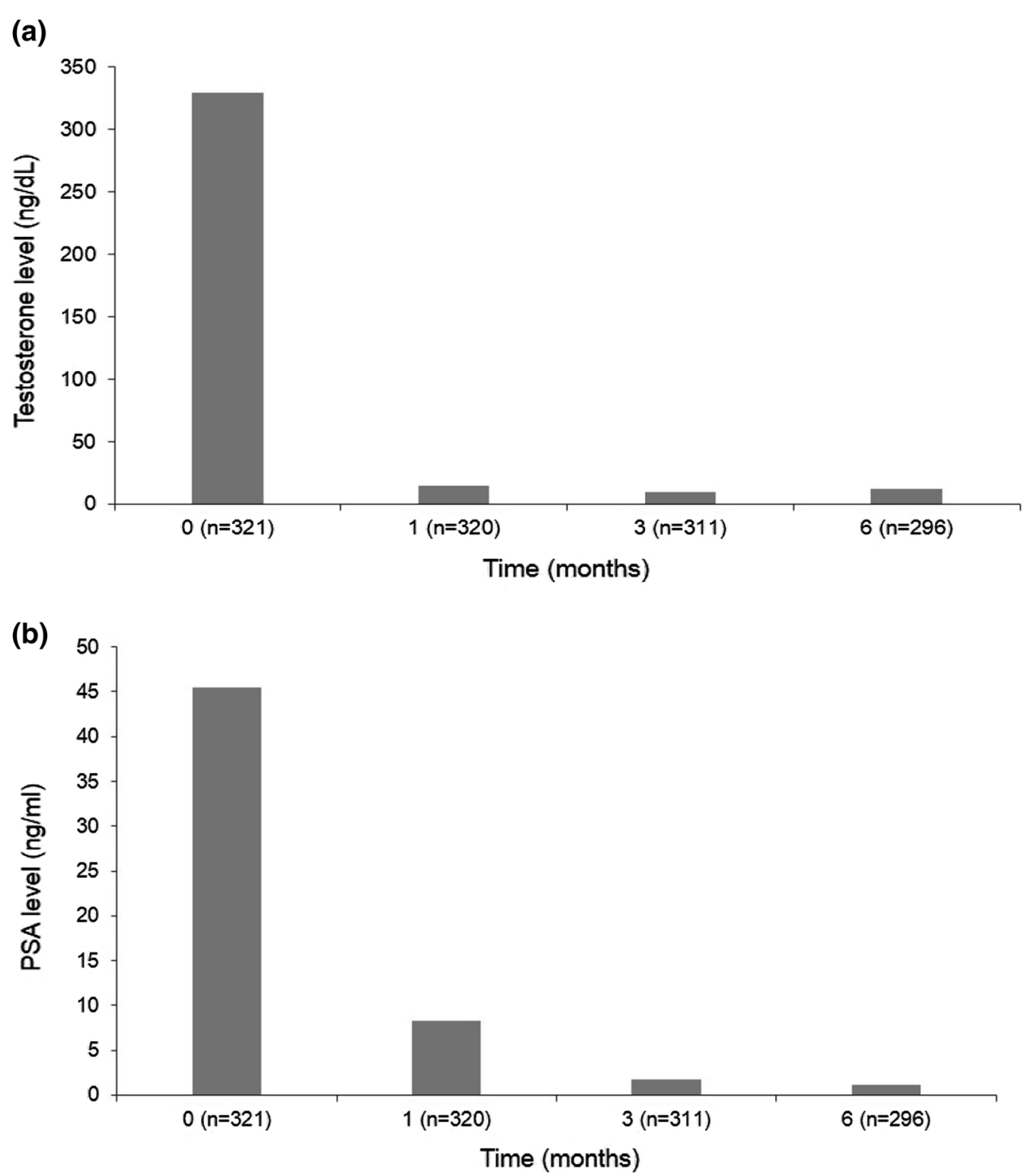

Fig. 2 Change in testosterone (a) and serum PSA (b) levels from baseline with sustained-release 22.5 mg 6-month triptorelin in men with advanced prostate cancer [42]. PSA prostate-specific antigen

triptorelin $11.25 \mathrm{mg}$ 3-month formulation and showed reductions in median PSA from $112.7 \mathrm{ng} / \mathrm{ml}$ at baseline to 10.4 and $11.6 \mathrm{ng} / \mathrm{ml}$ at 3 and 6 months, respectively [45]. Substantial PSA decreases were also observed with the triptorelin $22.5 \mathrm{mg}$ 6-month formulation from 84 days post-injection [15, 42] (Fig. 2). The longer term Triptocare LT study, which included 180 patients who had participated in and received triptorelin treatment in the
Triptocare study, showed that median serum PSA reductions were maintained after 3 years of ADT [44]. The median time to PSA nadir was 185 days [44].

All of the aforementioned efficacy data were reported with the IM administration of triptorelin. Recently, SC administration of triptorelin pamoate $11.25 \mathrm{mg}$ 3-month formulation was shown to achieve castrate levels of testosterone within 4 weeks of the 
first injection in $97.6 \%$ of men with locally advanced or metastatic prostate cancer [31]. Treated patients reached testosterone levels of $<50 \mathrm{ng} / \mathrm{dl}$ after a median of 22 days and maintained castration until study end at 26 weeks (in $96.6 \%$ of those who achieved castration at 4 weeks) [31]. Most patients $(77.7 \%)$ also met the stringent castration definition of testosterone concentration $<20 \mathrm{ng} / \mathrm{dl}$ at 4 weeks, increasing to $90.8 \%$ after 26 weeks. In this study, PSA levels were also reduced from baseline by $64.2 \%$ and $96.0 \%$ at 4 and 26 weeks after injection, with median PSA levels below $4 \mathrm{ng} / \mathrm{ml}$ from week 8 through week 26 [31]. These data suggest that the route of triptorelin administration can be switched from IM to SC without compromising efficacy.

\section{Effect on Symptoms}

Up to $40 \%$ of men with localized prostate cancer may have moderate or severe lower urinary tract symptoms (LUTS) [48], but data on the impact of ADT on LUTS are limited [49-51]. Recently, the preliminary results of an observational study in six countries suggested that treatment with triptorelin 1- and 3-month formulations improved LUTS after 6 and 12 months, as measured by a significant reduction in the International Prostate Symptom Score (IPSS) [52]. Interestingly, the improvement in LUTS after triptorelin therapy, correlated with reductions in PSA levels [52]. Similar results were observed in a prospective observational study that included 325 Belgian patients with locally advanced or metastatic prostate cancer, the majority of whom (62\%) had moderate (IPSS 8 -19) to severe (IPSS $\geq 20$ ) LUTS at study entry [53]. After 24 and 48 weeks of treatment with triptorelin $3.75 \mathrm{mg}$ and/or
$11.25 \mathrm{mg}$ formulations, mild or no LUTS were reported in $25.7 \%$ and $33.5 \%$ of patients, respectively [53].

The triptorelin 1- and 3-month formulations have also been associated with improvement in other clinical symptoms, including bone pain [40, 41, 45], but further study on bone pain relief is needed.

\section{Tolerability}

Across clinical trials of patients with advanced prostate cancer, sustained-release triptorelin 1-, 3- and 6-month formulations were generally well tolerated, and the safety profile is consistent between the sustained-release formulations [15, 28, 31, 40, 42, 54]. The most frequently occurring treatment-related adverse events (AEs) with both IM and SC administrations of triptorelin were characteristic of those observed following any GnRH agonist treatment and are due to the expected pharmacological effect of the drug, i.e., castration $[15,31]$. Such AEs with IM administration included hot flushes $(50 \%$ of patients), erectile dysfunction (4\%), and decreased libido (3\%) [26, 27]. Similarly, hot flushes $(10.3 \%)$ were the most frequently reported $\mathrm{AE}$ with the SC administration of triptorelin followed by increased weight (5.6\%) [31].

Despite these AEs, discontinuation rates while receiving triptorelin are infrequent. For example, the IM administered triptorelin $22.5 \mathrm{mg}$ 6-month formulation led to no withdrawals due to AEs in the pivotal trial of this formulation [15]. Equally, triptorelin $11.25 \mathrm{mg} 3$-month treatment did not lead to discontinuations due to AEs when administered by SC injection to patients with locally advanced or metastatic prostate cancer [31]. 


\section{Triptorelin in Routine Clinical Practice}

Reports of triptorelin efficacy in clinical trials translate to real-world studies. For example, in a grouped analysis of 1241 men from six countries, mean PSA levels were $117.9 \mathrm{ng} / \mathrm{ml}$ before the men initiated triptorelin therapy and this was reduced to 8.5 and $16.6 \mathrm{ng} / \mathrm{ml}$ after 6 and 12 months treatment, respectively [52]. A recent preliminary report from the UK indicated that PSA remained suppressed when patients switched from any 3-month formulation of GnRH agonist to the triptorelin $22.5 \mathrm{mg}$ 6-month formulation, and this switch may help reduce hospital resource use [55].

Studies of sustained-release formulations of triptorelin during routine clinical practice also demonstrate improvements in some aspects of health-related quality of life (HRQoL) and satisfaction in patients [52, 53, 55-58]. In an observational study of everyday practice in France, 1438 patients initiating treatment with triptorelin 3- or 6-month formulations for prostate cancer were evaluated for reasons for prescription and patient preference. Most patients initiated the 6-month formulation $(62.8 \%$ vs $37.2 \%$ for the 3-month formulation), primarily for physician-reported reasons relating to the simplification of the treatment regimen and fewer unnecessary visits. Most patients ( $\sim 80 \%)$ were satisfied with their prescribed formulation [57]. A second French longitudinal, prospective study of elderly men aged 75 years or older with prostate cancer observed that 3-6 months of triptorelin treatment did not adversely influence HRQoL. Notably, triptorelin treatment improved HRQoL related to urinary symptoms and incontinence [56].
One notable observation in many studies in routine practice is the low frequency of testosterone measurement-for example, in the Triptocare LT study, less than $20 \%$ of patients had testosterone levels measured at all time points [44]. Since testosterone level remains the primary biochemical surrogate efficacy parameter of medical castration in prostate cancer, the low frequency of testosterone measurement in practice is a concern. Greater efforts should be made to ensure testosterone measurement in future observational studies and registries to improve the quality of outcomes data, and initiatives, such as the Prostate Cancer Outcomes Registry-Australia and New Zealand, may help in this respect [59].

\section{ARE ALL ADTS THE SAME?}

Several head-to-head trials have been conducted of sustained-release 1-month triptorelin acetate or pamoate versus leuprolide acetate [39-41]. In the most recent study, 284 men with advanced prostate cancer were randomly assigned to receive triptorelin pamoate $3.75 \mathrm{mg}$ or leuprolide $7.5 \mathrm{mg}$ every 28 days for 9 months ( 252 days). Triptorelin and leuprolide demonstrated clinical equivalence in the proportion of men maintaining castrate serum testosterone levels, defined as $\leq 50 \mathrm{ng} / \mathrm{dl}$, between 2 and 9 months after starting treatment (mean levels maintained below castration limit in $98.8 \%$ vs $97.3 \%$ of the patients; cumulative maintenance castration rates of $96.2 \%$ vs 91.2\%, respectively). Changes in the secondary endpoints of LH levels, bone pain, PSA levels, and quality of life were also not significantly different between treatment 
groups. However, triptorelin was associated with a significantly higher 9-month survival rate than leuprolide $(97.0 \%$ vs $90.5 \%$; $P=0.033$ ) [40].

However, in general, there is a lack of head-to-head evaluations of GnRH agonists in advanced prostate cancer, and the aforementioned studies all used a 1-month formulation of triptorelin. In the absence of head-to-head data, cross-study comparisons suggest similar efficacy of the sustained-release 6-month formulations of the GnRH agonists triptorelin pamoate and leuprolide acetate, with medical castration rates (serum testosterone $\leq 50 \mathrm{ng} / \mathrm{dl}$ ) of $97.5 \%$ and $97.0 \%$ at 29 days and $98.3 \%$ and $99.0 \%$ at 12 months, respectively [60].

A technology appraisal commissioned by the National Institute for Health Care and Excellence (NICE) in the UK reviewed the evidence supporting the use of the GnRH antagonist degarelix for the treatment of advanced prostate cancer and selected leuprolide, goserelin, and triptorelin as comparators [61]. A mixed treatment comparison meta-analysis of a total of six studies of the selected agents revealed that leuprolide and goserelin were associated with increased mortality compared with degarelix (odds ratio [OR] 1.8 and 1.9, respectively). In contrast, mortality with triptorelin was lower than with degarelix (OR 0.5), leading the NICE Evidence Review Group to consider that the treatment effect of triptorelin on overall survival may differ from that of leuprolide and goserelin [61]. While this analysis is intriguing, more large-scale head-to-head comparisons would be needed to draw firm conclusions on the effects of different ADTs on survival.

\section{THE ONGOING PLACE OF ADT IN PROSTATE CANCER MANAGEMENT}

Two important topics on the role of ADT in prostate cancer management continue to be debated. First, whether tolerance and side effects of ADT can be diminished by altering the regimens used, for example, with intermittent ADT. Second, with the introduction of newer treatment options, mainly indicated for metastatic CRPC, there is a concern among clinical experts that some physicians may disregard the need for continued ADT (i.e., 'backbone ADT') [62].

The feasibility of intermittent ADT, as an alternative to continuous androgen deprivation for improving quality of life while maintaining disease control, was examined in 2013 in 1535 men with newly diagnosed metastatic hormone-sensitive prostate cancer, and was found to be inferior to continuous ADT on survival outcomes [63]. However, intermittent ADT may still have a role when patients are not metastatic, the patient profile fits the choice of strategy, or because of the strong belief that toxicity is reduced. This was tested in a secondary analysis of the trial mentioned above, with regard to toxicity. The analysis of intermittent versus continuous ADT suggested that the 10-year cumulative incidence of ischaemic and thrombotic events was significantly higher with intermittent ADT (33\%) versus continuous ADT $(24 \%, P=0.02)$. In conclusion, older men with metastatic prostate cancer who received intermittent ADT had no reduction in bone, endocrine or cognitive events, but ischemic and thrombotic events were more frequent compared with continuous ADT [64]. 
However, the results from these studies should be interpreted with caution, and there is a trend for improved HRQoL with intermittent versus continuous ADT and intermittent treatment may have reduced treatment costs [65]. These uncertainties have led the EAU to suggest that intermittent ADT may be an option in patients with metastatic disease after a standardized induction period [3].

Another strategy for the management of asymptomatic disease is to defer ADT until the development of symptoms. A Cochrane review of studies from the pre-PSA era suggested that early ADT in a metastatic population significantly reduced disease progression and associated complications [66]. However, the EAU guidelines highlight the difficulties in making any recommendations due to the lack of quality data [3].

On the issue of backbone ADT, the need to eliminate or suppress as many parts of the androgen receptor signaling pathway as possible provides a rationale for continuing androgen deprivation while inhibiting androgen biosynthesis with abiraterone [62]. Data suggest that the combination of abiraterone and ADT provides more sustained suppression of testosterone than abiraterone monotherapy [67-69]. Specifically, the use of abiraterone alone is not able to maintain decreased levels of testosterone in men who have not achieved castration, whereas the addition of abiraterone to backbone ADT results in sustained suppression of testosterone to low levels [67-69]. Likewise, the continuation of ADT when initiating enzalutamide therapy may help achieve greater $\mathrm{CAB}$.

The rationale for continuing ADT when starting chemotherapy in metastatic CRPC (mCRPC) is that cessation of ADT may cause renewed testosterone release and stimulation of the remaining androgen-sensitive elements of the tumor [62]. Although survival benefits of lowered testosterone in the setting of metastatic prostate cancer have not been conclusively demonstrated, improved overall survival by 13.6 months was shown with the inclusion of ADT during chemotherapy initiation compared with ADT alone in men with metastatic prostate cancer naïve to hormonal therapy from the CHAARTED (ChemoHormonal therapy versus Androgen Ablation Randomized Trial for Extensive Disease in prostate cancer) study (ClinicalTrials.gov identifier, NCT00309985) [70]. This study also showed an 8.5 month increase in median time to biochemical, symptomatic or radiographic progression with the addition of chemotherapy. In addition, the addition of chemotherapy to the first-line hormonal therapy for high-risk, locally advanced, metastatic or recurrent prostate cancer was shown to increase median overall survival by 10 months in the STAMPEDE trial (ClinicalTrials.gov identifier, NCT00268476) [71]. However, the incidence of Grade 3-5 AEs was considerably higher in the group receiving chemotherapy than in the group not receiving chemotherapy [71]. Thus, it seems the combination of ADT and chemotherapy should be initiated earlier in the treatment algorithm for high-risk disease. In patients who have already initiated ADT, it may be less clear if potential survival advantages exist by continuing ADT when chemotherapy is initiated, but it seems logical to follow expert guidance that advocates maintaining ADT when initiating chemotherapy for metastatic prostate cancer [62].

Irrespective of the above arguments in favor of maintaining backbone ADT, continuation of ADT, and maintenance of testosterone levels $<50 \mathrm{ng} / \mathrm{dl}$ were stipulated as inclusion criteria 
for entry into all randomized controlled trials of newer agents (e.g., abiraterone and enzalutamide) [20, 21, 72, 73], and therefore, there is no evidence to support stopping ADT when initiating these other agents. An important question that requires more data is whether certain sequences of these treatments or combinations of ADT and abiraterone and enzalutamide may benefit some patients. Several studies have assessed the optimal sequencing of treatments in different patient groups [74-77], but firm guidance is not currently possible.

As well as these issues surrounding ADT, the use of adjuvant ADT after radical prostatectomy when nodal involvement is detected continues to have an important role [3]. Similarly, adjuvant or neo-adjuvant ADT plus radiotherapy is established as standard practice for locally advance prostate cancer, especially when disease is classified as high risk [3, 78-81].

\section{CONCLUSION}

ADT remains the mainstay of treatment for advanced prostate cancer, with GnRH agonists predominating as a hormonal therapy of choice. Triptorelin is a GnRH agonist that is indicated as the first-line hormonal therapy in patients with locally advanced non-metastatic or metastatic disease. The availability of sustained-release 1-, 3- and 6-month formulations of triptorelin delivered via IM or SC routes offers the potential for improved flexibility and convenience for the patient with advanced prostate cancer. Moreover, sustained-release triptorelin treatment has a proven efficacy and safety profile in clinical trials, with observations from routine practice indicating patient satisfaction lending credence to clinical trial data. It is imperative that the emergence of new treatment options for castration-resistant prostate cancer does not lead physicians to overlook the benefits of continuing ADT in their patients. However, it is also clear that optimum treatment sequencing of ADT, novel hormonal agents, and chemotherapy needs to be defined and individualized for men with advanced prostate cancer.

\section{ACKNOWLEDGMENTS}

No funding or sponsorship was received for this study or publication of this article. Medical writing assistance for this study was provided by Martin Gilmour of ESP Bioscience, Crowthorne, UK and funded by Ipsen. During the peer review process, the manufacturer of the agent under review was offered an opportunity to comment on the article. Changes resulting from comments received were made by the author based on their scientific and editorial merit. All named authors meet the International Committee of Medical Journal Editors (ICMJE) criteria for authorship for this manuscript, take responsibility for the integrity of the work as a whole, and have given final approval for the version to be published.

Disclosures. Axel S. Merseburger and Marie C. Hupe have nothing to disclose.

Compliance with Ethics Guidelines. This article is based on previously conducted studies and does not involve any new studies of human or animal subjects performed by any of the authors.

Open Access. This article is distributed under the terms of the Creative Commons Attribution-NonCommercial 4.0 International 
License (http://creativecommons.org/licenses/ by-nc/4.0/), which permits any noncommercial use, distribution, and reproduction in any medium, provided you give appropriate credit to the original author(s) and the source, provide a link to the Creative Commons license, and indicate if changes were made.

\section{REFERENCES}

1. Ferlay J, Steliarova-Foucher E, Lortet-Tieulent J, et al. Cancer incidence and mortality patterns in Europe: estimates for 40 countries in 2012. Eur J Cancer. 2013;49:1374-403.

2. National Cancer Institute. SEER Stat Fact Sheet: Prostate Cancer. 2012. http://seer.cancer.gov/ statfacts/html/prost.html. Accessed 1 Dec 2016.

3. Mottet N, Bellmunt J, Briers E, et al. Guidelines on prostate cancer. 2016. Available at: https://uroweb. org/guideline/prostate-cancer/.

4. Huggins C, Hodges CV. Studies on prostatic cancer 1: the effect of castration, of estrogen and of androgen injection on serum phosphatases in metastatic carcinoma of the prostate. Cancer Res. 1941;19:293-7.

5. Sobin LH, Gospodarowicz MK, Wittlekind C. TNM classification of malignant tumors. 7th ed. Oxford: Wiley-Blackwell; 1999.

6. Lukka H, Warde P, Pickles T, et al. Controversies in prostate cancer radiotherapy: consensus development. Can J Urol. 2001;8:1314-22.

7. Delahunt B, Egevad L, Grignon DJ, Srigley JR, Samaratunga $\mathrm{H}$. Prostate cancer grading: recent developments and future directions. BJU Int. 2016;117(Suppl 4):7-8.

8. Ang M, Rajcic B, Foreman D, Moretti K, O'Callaghan ME. Men presenting with prostate-specific antigen (PSA) values of over 100 ng/mL. BJU Int. 2016;117(Suppl 4):68-75.

9. Bill-Axelson A, Holmberg L, Garmo H, et al. Radical prostatectomy or watchful waiting in early prostate cancer. N Engl J Med. 2014;370:932-42.

10. Wilt TJ, Brawer MK, Jones KM, et al. Radical prostatectomy versus observation for localized prostate cancer. N Engl J Med. 2012;367:203-13.
11. Hoffman KE, Niu J, Shen Y, et al. Physician variation in management of low-risk prostate cancer: a population-based cohort study. JAMA Intern Med. 2014;174:1450-9.

12. Aizer AA, Paly JJ, Michaelson MD, et al. Medical oncology consultation and minimization of overtreatment in men with low-risk prostate cancer. J Oncol Pract. 2014;10:107-12.

13. Gravis G, Boher JM, Fizazi K, et al. Prognostic factors for survival in noncastrate metastatic prostate cancer: validation of the glass model and development of a novel simplified prognostic model. Eur Urol. 2015;68:196-204.

14. Tunn UW, Wiedey K. Safety and clinical efficacy of a new 6-month depot formulation of leuprorelin acetate in patients with prostate cancer in Europe. Prostate Cancer Prostatic Dis. 2009;12:83-7.

15. Lundstrom EA, Rencken RK, van Wyk JH, et al. Triptorelin 6-month formulation in the management of patients with locally advanced and metastatic prostate cancer: an open-label, non-comparative, multicentre, phase III study. Clin Drug Investig. 2009;29:757-65.

16. Klotz L, Boccon-Gibod L, Shore ND, et al. The efficacy and safety of degarelix: a 12-month, comparative, randomized, open-label, parallel-group phase III study in patients with prostate cancer. BJU Int. 2008;102:1531-8.

17. Ockrim J, el Lalani N, Abel P. Therapy Insight: parenteral estrogen treatment for prostate cancera new dawn for an old therapy. Nat Clin Pract Oncol. 2006;3:552-63.

18. Akaza H, Hinotsu S, Usami $M$, et al. Combined androgen blockade with bicalutamide for advanced prostate cancer: long-term follow-up of a phase 3, double-blind, randomized study for survival. Cancer. 2009;115:3437-45.

19. Merseburger AS, Scher HI, Bellmunt J, et al. Enzalutamide in European and North American men participating in the AFFIRM trial. BJU Int. 2015;115:41-9.

20. Ryan CJ, Smith MR, de Bono JS, et al. Abiraterone in metastatic prostate cancer without previous chemotherapy. N Engl J Med. 2013;368:138-48.

21. Fizazi K, Scher HI, Molina A, et al. Abiraterone acetate for treatment of metastatic castration-resistant prostate cancer: final overall survival analysis of the COU-AA-301 randomised, double-blind, placebo-controlled phase 3 study. Lancet Oncol. 2012;13:983-92. 
22. Astellas Pharma. Xtandi (enzalutamide). Summary of product characteristics. 2015. Available at: http://www.ema.europa.eu/docs/en_GB/document _library/EPAR_-_Product_Information/human/002 639/WC500144996.pdf.

23. Merseburger AS, Bellmunt J, Jenkins C, Parker C, Fitzpatrick JM, European Treatment Practices G. Perspectives on treatment of metastatic castration-resistant prostate cancer. Oncologist. 2013;18:558-67.

24. Hotte SJ, Saad F. Current management of castrate-resistant prostate cancer. Curr Oncol. 2010;17(Suppl 2):S72-9.

25. Ipsen Ltd. Decapeptyl SR. $3 \mathrm{mg}$. Summary of product characteristics. 2015. Available at: https:// www.medicines.org.uk/emc/medicine/868.

26. Ipsen Ltd. Decapeptyl SR. $11.25 \mathrm{mg}$. Summary of product characteristics. 2015. Available at: https:// www.medicines.org.uk/emc/medicine/13851.

27. Ipsen Ltd. Decapeptyl SR. $22.5 \mathrm{mg}$. Summary of product characteristics. 2015. Available at: https:// www.medicines.org.uk/emc/medicine/24154.

28. Ploussard G, Mongiat-Artus P. Triptorelin in the management of prostate cancer. Future Oncol. 2013;9:93-102.

29. Romero E, Velez de Mendizabal N, Cendros JM, et al. Pharmacokinetic/pharmacodynamic model of the testosterone effects of triptorelin administered in sustained release formulations in patients with prostate cancer. J Pharmacol Exp Ther. 2012;342:788-98.

30. Bouchot O, Soret JY, Jacqmin D, Lahlou N, Roger M, Blumberg J. Three-month sustained-release form of triptorelin in patients with advanced prostatic adenocarcinoma: results of an open pharmacodynamic and pharmacokinetic multicenter study. Horm Res. 1998;50:89-93.

31. Lebret T, Rouanne M, Hublarov O, et al. Efficacy of triptorelin pamoate $11.25 \mathrm{mg}$ administered subcutaneously for achieving medical castration levels of testosterone in patients with locally advanced or metastatic prostate cancer. Ther. Adv Urol. 2015;7:125-34.

32. Lee CR. Thrombosis and anti-thrombotic therapy. In: Lee GR, Bithell TC, Foerster J, Athens JW, Lukens JN, editors. Wintrobe's clinical hematology. 9th ed. Philadelphia, PA: Lippincott Williams \& Wilkins; 1993. p. 1533.

33. Oefelein MG, Feng A, Scolieri MJ, Ricchiutti D, Resnick MI. Reassessment of the definition of castrate levels of testosterone: implications for clinical decision making. Urology. 2000;56:1021-4.

34. Morote J, Orsola A, Planas J, et al. Redefining clinically significant castration levels in patients with prostate cancer receiving continuous androgen deprivation therapy. J Urol. 2007;178:1290-5.

35. Dason S, Allard CB, Tong J, Shayegan B. Defining a new testosterone threshold for medical castration: Results from a prospective cohort series. Can Urol Assoc J. 2013;7:E263-7.

36. Bertaglia V, Tucci M, Fiori C, et al. Effects of serum testosterone levels after 6 months of androgen deprivation therapy on the outcome of patients with prostate cancer. Clin Genitourin Cancer. 2013;11(325-30):e1.

37. Boccardo F, Decensi A, Guarneri D, et al. Long-acting (depot) D-TRP-6 LH-RH (Decapeptyl) in prostate cancer. An Italian multicentric trial. Am J Clin Oncol. 1988;11(Suppl 2):S129-31.

38. Minkov NK, Zozikov BI, Yaneva Z, Uldry PA. A phase II trial with new triptorelin sustained release formulations in prostatic carcinoma. Int Urol Nephrol. 2001;33:379-83.

39. Kuhn JM, Abourachid $H$, Brucher $P$, et al. A randomized comparison of the clinical and hormonal effects of two GnRH agonists in patients with prostate cancer. Eur Urol. 1997;32:397-403.

40. Heyns CF, Simonin MP, Grosgurin P, Schall R, Porchet HC. Comparative efficacy of triptorelin pamoate and leuprolide acetate in men with advanced prostate cancer. BJU Int. 2003;92:226-31.

41. Abbou CC, Lucas C, Leblanc V. Tolerance and clinical and biological responses during the first 6 months of treatment with 1-month sustained release LHRH agonists leuprolerin and triptorelin in patients with metastatic prostate cancer. Prog Urol. 1997;7:984-95.

42. Martinez-Pineiro L, Schalken JA, Cabri P, Maisonobe $\mathrm{P}$, de la Taille A, Triptocare Study Group. Evaluation of urinary prostate cancer antigen-3 (PCA3) and TMPRSS2-ERG score changes when starting androgen-deprivation therapy with triptorelin 6-month formulation in patients with locally advanced and metastatic prostate cancer. BJU Int. 2014;114:608-16.

43. Botto H, Roupret M, Mathieu F, Richard F. Multicentre randomized trial comparing triptorelin medical castration versus surgical castration in the treatment of locally advanced or 
metastatic prostate cancer. Prog Urol. 2007;17:235-9.

44. de la Taille A, Martinez-Pineiro L, Cabri P, Houchard A, Schalken J. Factors predicting progression to castrate-resistant prostate cancer in patients with advanced prostate cancer receiving long-term androgen deprivation therapy. BJU Int. 2016 (epub ahead of print).

45. Kao CC, Chang $\mathrm{YH}, \mathrm{Wu} \mathrm{T}$, et al. Open, multi-center, phase IV study to assess the efficacy and tolerability of triptorelin in Taiwanese patients with advanced prostate cancer. J Chin Med Assoc. 2012;75:255-61.

46. Teillac P, Heyns CF, Kaisary AV, Bouchot O, Blumberg J. Pharmacodynamic equivalence of a decapeptyl 3-month SR formulation with the 28-day SR formulation in patients with advanced prostate cancer. Horm Res. 2004;62:252-8.

47. Mounedji N, Lundstrom EA, Purcea D, Grosgurin P, Porchet HC. Efficacy of triptorelin in lowering serum testosterone (sT) in patients with advanced prostate cancer. J Clin Oncol. 2011;29(Suppl. 7):A162.

48. Lehrer S, Stone NN, Droller MJ, Stock RG. Association between American Urologic Association (AUA) urinary symptom score and disease stage in men with localized prostate cancer. Urol Oncol. 2002;7:73-6.

49. Axcrona K, Aaltomaa S, da Silva CM, et al. Androgen deprivation therapy for volume reduction, lower urinary tract symptom relief and quality of life improvement in patients with prostate cancer: degarelix vs goserelin plus bicalutamide. BJU Int. 2012;110:1721-8.

50. Mason M, Maldonado Pijoan X, Steidle C, et al. Neoadjuvant androgen deprivation therapy for prostate volume reduction, lower urinary tract symptom relief and quality of life improvement in men with intermediate- to high-risk prostate cancer: a randomised non-inferiority trial of degarelix versus goserelin plus bicalutamide. Clin Oncol (R Coll Radiol). 2013;25:190-6.

51. Anderson J, Al-Ali G, Wirth $\mathrm{M}$, et al. Degarelix versus goserelin (+antiandrogen flare protection) in the relief of lower urinary tract symptoms secondary to prostate cancer: results from a phase IIIb study (NCT00831233). Urol Int. 2013;90:321-8.

52. Gil T, Aoun F, Cabri P, Maisonobe P, van Velthoven R. A prospective, observational grouped analysis to evaluate the effect of triptorelin on lower urinary tract symptoms in patients with advanced prostate cancer. Ther Adv Urol. 2015;7:116-24.
53. Peltier A, Aoun F, De Ruyter V, Cabri P, Van Velthoven R. Triptorelin in the relief of lower urinary tract symptoms in advanced prostate cancer patients: the result study. Prostate Cancer. 2015;2015:978194.

54. Shore ND, Sieber P, Schimke L, Perzin A, Olsen S. Comparison of tolerability and adverse events following treatment with two GnRH agonists in patients with advanced prostate cancer. Urol Nurs. 2013;33(236-44):48.

55. Cornford P, Jefferson K, Cole O, Gilbody JS, Nayar V, Auddy G. Switching to a 6-monthly triptorelin formulation for prostate cancer (Pca) reduces patient-Nhs interactions and hospital resource use: real world evidence (Rwe) from project deserve (decapeptyl service evaluation). Value Health. 2015;18:A483.

56. Lebret T, Culine S, Davin JL, et al. Quality of life of 1276 elderly patients with prostate cancer, starting treatment with a gonadotropin-releasing hormone agonist: results of a French observational study. Aging Male. 2014;17:87-93.

57. Lebret T, Davin JL, Hennequin C, et al. Selection criteria for initiation and renewal of luteinizing hormone-releasing hormone agonist therapy in patients with prostate cancer: a French prospective observational study. Ther Adv Urol. 2014;6:205-14.

58. Eisenhardt A, Schneider T, Scheithe K, Colling C, Heidenreich A, Studiengruppe T. Quality of life of patients with prostate cancer under androgen deprivation with GnRH analogues: Results of the noninterventional study TRIPTOSIX. Urologe A. 2016;55:176-83.

59. Evans SM, Nag N, Roder D, et al. Development of an international prostate cancer outcomes registry. BJU Int. 2016;117(Suppl 4):60-7.

60. Crawford ED, Phillips JM. Six-month gonadotropin releasing hormone (GnRH) agonist depots provide efficacy, safety, convenience, and comfort. Cancer Manag Res. 2011;3:201-9.

61. Uttley L, Whyte S, Gomersall T, et al. Degarelix for treating advanced hormone-dependent prostate cancer: a single technology appraisal. Sheffield, UK: ScHARR, University of Sheffield; 2013.

62. Merseburger AS, Hammerer P, Rozet F, et al. Androgen deprivation therapy in castrate-resistant prostate cancer: how important is GnRH agonist backbone therapy? World J Urol. 2015;33:1079-85.

63. Hussain $M$, Tangen CM, Berry DL, et al. Intermittent versus continuous androgen deprivation in prostate cancer. $\mathrm{N}$ Engl $\mathrm{J}$ Med. 2013;368:1314-25. 
64. Hershman DL, Unger JM, Wright JD, et al. Adverse health events following intermittent and continuous androgen deprivation in patients with metastatic prostate cancer. JAMA Oncol. 2016;2:453-61.

65. Brungs D, Chen J, Masson P, Epstein RJ. Intermittent androgen deprivation is a rational standard-of-care treatment for all stages of progressive prostate cancer: results from a systematic review and meta-analysis. Prostate Cancer Prostatic Dis. 2014;17:105-11.

66. Kunath F, Grobe HR, Rucker G, et al. Non-steroidal antiandrogen monotherapy compared with luteinising hormone-releasing hormone agonists or surgical castration monotherapy for advanced prostate cancer. Cochrane Database Syst Rev. 2014;6:CD009266.

67. O'Donnell A, Judson I, Dowsett M, et al. Hormonal impact of the 17alpha-hydroxylase/C $(17,20)$-lyase inhibitor abiraterone acetate (CB7630) in patients with prostate cancer. Br J Cancer. 2004;90:2317-25.

68. Ryan CJ, Peng W, Kheoh T, et al. Androgen dynamics and serum PSA in patients treated with abiraterone acetate. Prostate Cancer Prostatic Dis. 2014;17:192-8.

69. Sonpavde G, Attard G, Bellmunt J, et al. The role of abiraterone acetate in the management of prostate cancer: a critical analysis of the literature. Eur Urol. 2011;60:270-8.

70. Sweeney CJ, Chen YH, Carducci M, et al. Chemohormonal therapy in metastatic hormone-sensitive prostate cancer. N Engl J Med. 2015;373:737-46.

71. James ND, Sydes MR, Clarke NW, et al. Addition of docetaxel, zoledronic acid, or both to first-line long-term hormone therapy in prostate cancer (STAMPEDE): survival results from an adaptive, multiarm, multistage, platform randomised controlled trial. Lancet. 2016;387:1163-77.

72. Scher HI, Fizazi K, Saad F, et al. Increased survival with enzalutamide in prostate cancer after chemotherapy. N Engl J Med. 2012;367:1187-97.

73. Beer TM, Armstrong AJ, Rathkopf DE, et al. Enzalutamide in metastatic prostate cancer before chemotherapy. N Engl J Med. 2014;371:424-33.

74. Azad AA, Eigl BJ, Murray RN, Kollmannsberger C, Chi KN. Efficacy of enzalutamide following abiraterone acetate in chemotherapy-naive metastatic castration-resistant prostate cancer patients. Eur Urol. 2015;67:23-9.

75. Caffo O, De Giorgi U, Fratino L, et al. Clinical outcomes of castration-resistant prostate cancer treatments administered as third or fourth line following failure of docetaxel and other second-line treatment: results of an Italian multicentre study. Eur Urol. 2015;68:147-53.

76. Zhang T, Dhawan MS, Healy P, et al. Exploring the clinical benefit of docetaxel or enzalutamide after disease progression during abiraterone acetate and prednisone treatment in men with metastatic castration-resistant prostate cancer. Clin Genitourin Cancer. 2015;13:392-9.

77. Cheng HH, Gulati R, Azad A, et al. Activity of enzalutamide in men with metastatic castration-resistant prostate cancer is affected by prior treatment with abiraterone and/or docetaxel. Prostate Cancer Prostatic Dis. 2015;18:122-7.

78. Bolla M, Van Tienhoven G, Warde P, et al. External irradiation with or without long-term androgen suppression for prostate cancer with high metastatic risk: 10-year results of an EORTC randomised study. Lancet Oncol. 2010;11:1066-73.

79. Denham JW, Steigler A, Lamb DS, et al. Short-term neoadjuvant androgen deprivation and radiotherapy for locally advanced prostate cancer: 10-year data from the TROG 96.01 randomised trial. Lancet Oncol. 2011;12:451-9.

80. Roach M 3rd, Bae K, Speight J, et al. Short-term neoadjuvant androgen deprivation therapy and external-beam radiotherapy for locally advanced prostate cancer: long-term results of RTOG 8610 . J Clin Oncol. 2008;26:585-91.

81. Pilepich MV, Winter K, Lawton CA, et al. Androgen suppression adjuvant to definitive radiotherapy in prostate carcinoma-long-term results of phase III RTOG 85-31. Int $J$ Radiat Oncol Biol Phys. 2005;61:1285-90.

82. National Center for Biotechnology Information. PubChem Compound Database. https://pubchem. ncbi.nlm.nih.gov/compound/25080282. Accessed 26 May 2016.

83 National Center for Biotechnology Information. PubChem Compound Database. https://pubchem. ncbi.nlm.nih.gov/compound/25074469. Accessed 26 May 2016. 